\title{
An Indigenous Insight into the Opiod Crisis and the Rehabilitation of the Soul
}

\author{
Jay Hansford C Vest* \\ Professor of American Indian Studies, University of North Carolina, USA \\ *Corresponding author: Jay Hansford C Vest, Professor of American Indian Studies, University of North Carolina, USA
}

\section{Short Communication}

Bornof orality, Native American shamanic traditions and healing practices are exclusively organic in manifestation [1]. In this context, the healing ritual assumes an organicism [2] where reality is found in the presence of the object as opposed to the Cartesian fantasy whereby reality is divorced from the organically manifest object [3].

As a result, in these traditions the healing ritual assume an organic based manifestation in herbal application as opposed to a faith-based miracle. However among many Native American shamans there is the practice of astral projection in a process centered metaphysic of nature [4] commonly known as "telescoping" wherein the shaman projects his or her free soul into the netherworld to investigate the wellbeing of his or her clients or patients. As a means to engage astral projection, the shaman commonly employs a smudged derive from selected herbal and or fungal flora [5]. For instance, this counch that grows on dead stum Once, ps and dying trees is commonly gathered for this explicit purpose in what the Cree refer to as "The shaking tent ritual" [6]. Once, for example, when teaching a summer session at the University of Lethbridge in Alberta, I was introduced to a Cree shaman by a student who was his son-in-law and who was a previous acquaintance, whom I had met at a healing ritual in Montana. The man, my student, had come to meet a Blackfeet healer, Buster Yellow Kidney, whom I was associated with at the time; he was seeking medical assistance from my shamanic friend - Buster. It was a time when I was assisting Buster with his preparations including preparing the lodge and tending its protocol; the winds were high, and I was having trouble getting the fire lit so that they would be patient was trying to help me. Later he went shopping at a supply store and brought me an extended reach lighter to make igniting the fires easier. Upon my arrival at Lethbridge, he introduced me to his father-in-law, an elderly Cree shaman named John, who invited me to go with him to gather the tree counch fungus used in telescoping. We went to the forested foothills of the Rockies, where we expected to find the fungi. Locating a suitable crop, we began our gathering of the medicine and while taking a break, the old man stopped to wind his pocket watch. Although I watched him wind the timepiece, I did not see him return it to his pocket and shortly afterwards he decided we had harvested enough of the medicine and indicate it was tied to return to the truck. We began gathering up our things and the supply of medicine to return to the vehicle. As we reached the truck it was growing dark and it was then that old John missed his watch. Assuming he had left it on the stump, we decided we would come back for it in the daylight and mounted the truck to return home. During dinner, John was anxious about the watch and immediately after finishing the meal, he excused himself to retire to his bedroom where he intended to telescope the watch so as to facilitate its recovery on the next day as he expected he could lead us directly to the lose object as a result of his astral projection that evening. As we waited in the kitchen, we smelled the smudge and heard the medicine chants of his telescoping. Taking to our sleeping berths, we retired for the night but in the morning at breakfast, John was in possession of his watch having awoke to find it on the nightstand by his bed. It was explained he had traveled to the site and carried the object home while in his astral state. In effect, he had teleported the object home during the previous evening while engaging the telescoping ritual thereby giving testament to his shamanic power. Indeed, John has manifested the power of kinetic teleportation, rare in today's world but common to many ancient pre-colonial shamans. In the recovery of the watch, I have never had reason to doubt john'veracity as in my observations his dealings with others were always explicitly honest and respectful to others. His extraordinary shamanic powers were nonetheless manifest via the watch incident wherein he engaged his spirit helpers to assist him teleporting the watch home while in a state of astral flux. Explanation of this shamanic feat may be understood within the framework of a Native metaphysic of nature [7] rather than a mind over matter Cartesian miracle [8].

In the context of this study, I have offered the foregoing story as a prelude to events leading to my insight into an indigenous interdiction into opoid experimentation and addiction. While 
teaching at Hamilton College nearby Oneida, New York, my wife and I lived in college owned housing situated within the campus infrastructure - to some extent, it was something like life in the fishbowl, however students did not make a habit of visiting faculty at their homes, but they did have an idea of the residence of respective faculty; hene, one evening there was a call upon my home by one of my former students who was aware of Native religious traditions as per instruction within my course. He had experienced a disturbing event that led him to seek my help. Distressed from opiod experimentation, Jon, having recalled my instruction into shamianic healing, came calling at my home that evening to seek a traditional interdiction into his crisis of course was not bound to assist him but I did feel an obligation to listen to his narrative so that over my wife's protests, I invited him into our home. In keeping with the traditional protocol, I prepared both a sage and a sweetgrass smudge to purify the environment as we spoke. As the smudge scented the room, Jon explained his distress to me, confessing that he feared he was no longer whole and that something was missing from within him. As I listened to his plight, it became clear to me that the best course of action was to telescope the problem. At first my wife a trained physician was against it but knowing my indigenous attachment to Native medicine, she relented and left me to my retirement to the bedroom to telescope the problem. Not being a Native, she had learned it was important to give me this latitude that I might successfully engage the ritual. Jon had departed with the promise to contact me during the next week so we together might evaluate the findings. Engaguing the counch smudge, I rested in a trance - sleep no sleep state- wherein two visions over helmed me with images of Jon's opiod experminentation. Following my chant, I found myself in the old cemetery on campus where Chief kenadoah rested nearby Rev. Kirkland as founders of the College-known then as Hamilton Onieda Academy with a charter to educate Indians. In my astral state wat the cemetar, beheld an image of Jon standing beneath an ancient elm-something out of Longfelloe's "Sleepy Hollow" - I surmised and as I looked on at him there was something odd or missing. All the graves featured a small orange disc above the hurst in front of the tombstones but looking agai at Jon, I noticed he had no orange light or disc about him and with this observation I knew he was missing his free soul. The second vision put me adjacent to the old quad standing on the cafiteria grounds looking east at a venerable old dorm where I observed an orange disc near the ground floor rise up through the building to exit the roof and I knew it was here he had made his opiod experimentation. Afterwards I consulted with my wife and given her clinical psychology send specialization she offered that such drugs have an effect on the soul saying these drugs excite the soul pushing it to exit the body - hence I offered we must have many soulless people in our society as a product of this opiod crisis. Back on campus in coming days Jon came to see me and as before I observed a sage and sweet grass smudge protocol before discussing my findings with him. 0 put it mildly he was astonished at what I had seen informing me he had gone with some others to the cemetery following the injection of heroin and I had confirmed his soulless state as thre opied had taken effect upon him. Missing his shadow, he was divorced from his organic existence within the natural world and this frightened me. It was shadow sickness aas a result of the drug. My advice to him was to return to the old elm and there make tobacco offerings - he would need to connect with his shadow and welcome it home or so I advised. to the spirits that he might attract his shadow's return and reunification but I could help him no more as I was leaving the college to take a new post in North Carolina. It was a tricky situation as the power needed wait to restore his shadow was then beyond my iniation into the arts and it could pose a risk to me, if I proceeded without an adequate expertise.

In jon's case, I had divined his opiod expermentation during a shamanic trance and freelygiven my advice to him that he might recover his shadow in theplace where it had been found missing - hallowed ground with the remains of Chief Skenadoah and Rev. Kirkland; hence he had helpers there who might serve to facilitate his recovery. Although I have not seen him since, I learned he did graduate and today enjoys normal life in his original home local of New York City. As a result, I like to think the shamanic interdiction that revealed his shadow sickness was ultimately successful and it may indicate a treatment for lost and disponded suffers of shadow sickness.

\section{References}

1. Vest Jay Hansford C (2014) Native American oralcy: Interpreting Indigenous Thought. Vernon, BC: J Charlton Publishing, LTD, UK.

2. Whitehead Alfred North (1925) Science and the Modern World.

3. Give citation of this problem - e.g. cite Descarte via Abram.

4. Brown Joseph Epes (1982) The Spiritual Legacy of the American Indian. Indian cosmology pp. 135.

5. Indentify and cite the tree counch fungi involved.

6. Cite Cree shaking tent ritual.

7. Brown (1925) The Spiritual Legacy of the American Indian (crossroad) and by the process metaphysic of Whitehead Alfred North (1982) Science and the Modern World.

8. Cite De Cartes. 


\section{(c) (1) This work is licensed under Creative}

To Submit Your Article Click Here: Submit Article

DOI: 10.32474 /JAAS.2020.01.000116

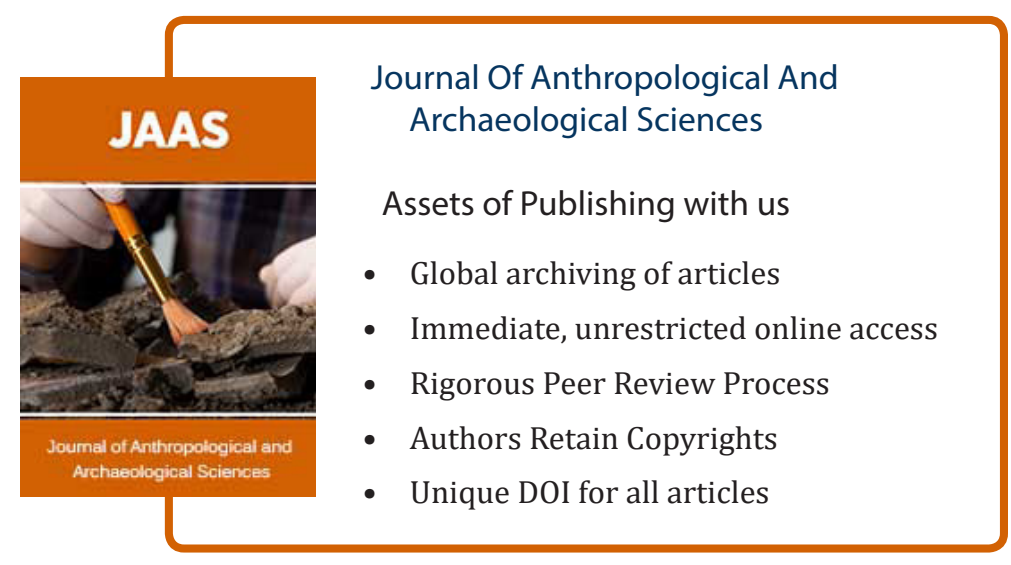

